\title{
Habituation and dishabituation of the human orienting reflex under instruction-induced stress
}

\author{
H. D. KIMMEL and MICHAEL BEVILL \\ University of South Florida, Tampa, Florida
}

\begin{abstract}
Twenty subjects received habituation trials with a $1000-\mathrm{Hz}$ tone until two consecutive nonresponses (skin conductance response) occurred. Then a single, novel $1400-\mathrm{Hz}$ tone was administered, followed by another presentation of the $1000-\mathrm{Hz}$ tone. Half the subjects were told that an intelligence test would follow. All of the subjects were initially given the STAI trait anxiety test. The 10 subjects told to expect an intelligence test needed significantly more trials to habituate and made significantly larger SCRs to the novel stimulus than did the other 10 subjects. Trait anxiety neither interacted with these effects nor had any effects of its own. The absence of trait anxiety effects was interpreted as being in disagreement with Spielberger's assertions regarding trait and state anxiety.
\end{abstract}

Habituation of the skin conductance response (SCR) component of the human orienting reflex (OR) is retarded when very intense or highly variable stimuli are used (Ray, 1979; Ray, Piroch, \& Kimmel, 1977), or when the stimuli are separated by long rather than short time intervals (Ray, 1979). OR habituation is also substantially slowed if the subject performs a stimulus-related task (Ray, Piroch, \& Kimmel, 1977).

The task effect could be due either to an increase in sensitivity to the stimuli mediated by "significance" or to an elevation of generalized arousal level. An increase in general arousal would result in larger reactions to all stimuli. Assuming response-scoring equipment of fixed sensitivity, subjects making larger responses would require greater numbers of trials before their responses fell below the scoring system's threshold. A variety of stressors could cause this type of generalized effect on OR habituation.

For example, generalized psychological stress could be induced by telling the subject that an evaluation of his/her ability was going to be conducted in a later phase of the experimental session. The present study investigated the effect of such instructions on habituation of the SCR to an innocuous auditory stimulus and on the dishabituation effect of changing the stimulus following habituation. Since individuals with High Trait Anxiety Inventory (STAI; Spielberger, 1970) scores are assumed to be more susceptible to "ego threat" than those with low STAI scores (Spielberger, 1972), STAI scores were used to divide the subjects into two groups. Half of each of these

This report is based on the second author's Honors Thesis, University of South Florida.

H. D. Kimmel's mailing address is: Department of Psychology, University of South Florida, Tampa, FL 33620. anxiety groups received the stressful instructions and the other half of each anxiety group did not.

It was hypothesized that instructions regarding a forthcoming evaluation of one's ability would retard simple OR habituation by increasing general arousal. This increase in arousal was also expected to be manifested in a larger reaction to a novel, disinhibiting stimulus administered following habituation. On the assumption that trait anxiety identifies differences in susceptibility to egothreatening situations, the OR habituation and dishabituation effects were expected to be greater in subjects with high trait anxiety scores than in those with lower scores.

\section{METHOD}

\section{Subjects}

Twenty female university students volunteered for the experiment to earn extra class credit. Prior to the habituation procedure, the subjects completed the trait form of the STAI. The two highest scoring subjects were assigned to a pair, the next two highest to the next pair, etc., down to the two lowest scoring subjects. Within each pair, subjects were assigned randomly to the stress and no-stress conditions.

\begin{abstract}
Apparatus
The SCR was picked up as a dc resistance change by $1.9-\mathrm{cm}$ zinczinc sulfate electrodes in Lucite cups filled with saline jelly. The cups were attached by rubber straps to the palm and back of the subject's nonpreferred hand. The response was amplified by a Biophysical GSR amplifier and recorded on a Texas Instruments RectiRiter with a paper speed of $15.2 \mathrm{~cm} / \mathrm{min}$. Current density = $2.84 \mu \mathrm{A} / \mathrm{cm}^{2}$.

The habituation stimulus was a 4-sec $1000-\mathrm{Hz}$ pure tone of approximately $60 \mathrm{~dB}$, produced by a BRS Foringer Audio Generator, Model AU-902, and delivered via a wall-mounted speaker above and behind the subject's head. A 4-sec $1400-\mathrm{Hz}$ tone of equal intensity was used as the novel stimulus.
\end{abstract}

\section{Procedure}

Data were collected in a sound-attenuated chamber, with the sub- 
ject seated in a comfortable easy chair. The subject was told that her reactions to sound would be measured and that she should try to relax and sit quietly. The subjects in the stress condition were additionally told that an intelligence test would be given immediately following the habituation procedure.

The habituation procedure consisted of at least 8 and no more than 40 presentations of the $1000-\mathrm{Hz}$ tone at randomized intervals between 40 and $60 \mathrm{sec}$ (mean $=50 \mathrm{sec}$ ) until the criterion of habituation (two consecutive zero responses) was attained. Five seconds after the last habituation tone, the novel $1400 \mathrm{~Hz}$ was presented. Following the next interval of between 40 and $60 \mathrm{sec}$, the original $1000-\mathrm{Hz}$ tone was presented one more time.

Subsequently, the subject was informed that the habituation procedure was over and, after being asked not to discuss the procedure with anyone, was dismissed.

\section{RESULTS}

An SCR was defined as the maximum increase in log conductance occurring between 1.0 and $5.0 \mathrm{sec}$ after stimulus onset. For analysis and presentation in this report, these scores were multiplied by 1,000 .

\section{Trials to Criterion}

Table 1 shows the average number of trials to reach the habituation criterion under the stress and no-stress conditions, in subgroups formed by dividing at the median trait anxiety score. The stress instruction resulted in about twice as many trials being needed for habituation. Trait anxiety was unrelated to the number of trials to habituation.

Analysis of variance of the number-of-trials data showed that the effect of stress instructions was significant $[\mathrm{F}(1,16)=9.94, \mathrm{MSe}=13.6, \mathrm{p}<.05]$. The $\mathrm{F}$ ratios for trait anxiety and the anxiety $\times$ stress interaction were both less than 1.0.

\section{SCR Magnitudes on First Two Trials}

Since habituation was very rapid, especially in the nostress condition, only the first two trials could be em-

Table 1

Average Number of Trials to Habituation in High and Low Trait Anxiety Subjects Under Stress and No-Stress Conditions

\begin{tabular}{lcc}
\hline & \multicolumn{2}{c}{ Trait Anxiety } \\
\cline { 2 - 3 } Instruction & High & Low \\
Stress & (Above Median) & (Below Median) \\
No Stress & 10.2 & 10.2 \\
& 4.0 & 6.0 \\
\hline
\end{tabular}

Table 2

Mean SCR Magnitude $(\log \Delta \mathrm{C} \times 1,000)$ on Trials 1 and 2, in High and Low Trait Anxiety Subjects Under Stress and No-Stress Conditions

\begin{tabular}{clcc}
\hline Subjects & Condition & Trial 1 & Trial 2 \\
\hline \multirow{2}{*}{ High Anxiety } & Stress & 243 & 205 \\
& No Stress & 115 & 32 \\
\multirow{2}{*}{ Low Anxiety } & Stress & 338 & 275 \\
& No Stress & 243 & 162 \\
\hline
\end{tabular}

Table 3

Mean SCR Magnitude $(\log \Delta C \times 1,000)$ in Response to Novel Stimulus in High and Low Trait Anxiety Subjects Under Stress and No-Stress Conditions

\begin{tabular}{lcc}
\hline & \multicolumn{2}{c}{ Trait Anxiety } \\
\cline { 2 - 3 } Instruction & High & Low \\
(Above Median) & (Below Median) \\
\hline Stress & 169 & 128 \\
No Stress & 0 & 7 \\
\hline
\end{tabular}

Table 4

Mean SCR Magnitude $(\Delta \log C \times 1,000)$ in Response to the 1000-Hz Tone Immediately Following the Dishabituation Trial, in High and Low Trait Anxiety Subjects Under Stress and No-Stress Conditions

\begin{tabular}{lcc} 
& \multicolumn{2}{c}{ Trait Anxiety } \\
\cline { 2 - 3 } Instruction & High & Low \\
(Above Median) & (Below Median) \\
\hline Stress & 32 & 42 \\
No Stress & 0 & 6 \\
\hline
\end{tabular}

ployed to determine SCR magnitudes evoked by the tone. Table 2 shows the average SCR magnitudes on Trials 1 and 2 in the high and low trait anxiety subgroups under the stress and no-stress conditions. Although there was a consistent reduction from Trial 1 to Trial 2 in response strength in all cases, analysis of variance showed that this habituation effect was not statistically significant. The apparent difference in response magnitude due to stress instructions also did not attain statistical significance $[\mathrm{F}(1,16)=2.73]$.

\section{SCR Evoked by Novel Stimulus}

Table 3 shows the average SCR evoked by the novel $1400-\mathrm{Hz}$ tone in the high and low trait anxiety groups in the stress and no-stress conditions. The subjects in the nostress condition hardly responded at all to the $1400-\mathrm{Hz}$ tone, while the subjects in the stress condition responded to the novel stimulus. Analysis of variance of these SCR magnitude data showed that the stress effect was significant $[\mathrm{F}(1,16)=4.81, \mathrm{MSe}=21,765, \mathrm{p}<.05]$, but the anxiety and stress $\times$ anxiety interaction Fs were both less than 1.0 .

\section{SCR Magnitude on Trial Following Novel Stimulus}

The $1000-\mathrm{Hz}$ tone was again presented following the single administration of the novel stimulus. Table 4 shows the average SCR evoked by the $1000-\mathrm{Hz}$ tone following the dishabituation trial, for high and low trait anxiety subjects in the stress and no-stress conditions. Analysis of variance shows that the apparent stress effect was not significant $[F(1,16)=2.90]$.

\section{DISCUSSION}

The results of this study support the conclusion that instructions regarding an impending intelligence test result 
in retardation in habituation of the orienting reflex and in enhancement of responding to a dishabituating novel stimulus following habituation.

Subjects told that the habituation procedure would be followed by an intelligence test required about twice as many trials to achieve the criterion of habituation (mean $=10$ ) as did controls who were not given this instruction $($ mean $=5)$. This difference is approximately as great as is produced by varying some dimension of the stimulus (Ray, Piroch, \& Kimmel, 1977). Furthermore, the subjects who were given the intelligence-test instructions made significantly larger responses to a novel, dishabituating stimulus than did the controls. The subjects placed under the instructional stress of an impending test of their ability also tended to make larger SCRs than the nonstressed controls during habituation and following dishabituation, although neither of these differences attained statistical significance.

The assumption that instructions regarding an impending intelligence test would have a greater effect on subjects with higher trait anxiety scores than on those with lower scores was not borne out. The STAI trait measures had no influence either on number of trials to habituation or on any of the SCR magnitude measures, nor did trait anxiety interact with the two instructional stress effects that actually were statistically significant. This negative outcome is interpreted as being in fundamental disagreement with Spielberger's (1972) assertion that "ego threat" differentially influences high and low trait anxious individuals. The basis for this negative conclusion is the fact that the instructional stress (i.e., informing the subject that an intelligence test would follow the nabituation phase of the procedure) had a significant influence on both the number of trials to the habituation criterion and on the magnitude of the SCR to the novel stimulus following attainment of the criterion. Yet, neither of these effects interacted with the trait anxiety dimension, nor did trait anxiety, itself, have any effect on habituation.

The results of this study confirm that it is relatively easy to retard habituation of the OR in humans. Factors relating to the stimulus (intensity, variability), to the interval between stimuli, and to the psychological setting (instructions) have now all been shown to be capable of retarding habituation relative to control or standard conditions. The wide range of difference among these factors suggests that no single underlying mechanism is likely to be involved in all of their effects, although Sokolov's (1963) comparison model of OR habituation appears to be capable of embracing them all.

\section{REFERENCES}

RAY, R. L. (1979). The effect of stimulus intensity and intertrial interval on long-term retention of the OR. In H. D. Kimmel, E. H. van Olst, \& J. F. Orlebeke (Eds.), The orienting reflex in humans (pp. 373-379). Hillsdale, NJ: Erlbaum.

RaY, R. L., Piroch, J. F., \& Kimmel, H. D. (1977). The effect of task and stimulus variability on habituation of electrodermal and vasomotor reactions. Physiological Psychology, 5, 189-196.

Sokolov, E. N. (1963). Perception and the conditioned reflex (S. W. Waydenfeld, Trans.). New York: Macmillan.

SPIElBerger, C. D. (1970). State-Trait Anxiety Inventory. Palo Alto: Consulting Psychologists Press.

Spielberger, C. D. (Ed.) (1972). Anxiety: Current trends in theory and research (Vol. 2). New York: Academic Press.

(Manuscript received November 22, 1984; revision accepted for publication April 21, 1985.) 